\title{
Predicting speech intelligibility in university classrooms using geometrical acoustic simulations
}

\author{
Giulia Fratoni ${ }^{1}$, Dario D'Orazio ${ }^{1}$, Domenico De Salvio ${ }^{1}$, Massimo Garai ${ }^{1}$ \\ ${ }^{1}$ Department of Industrial Engineering, University of Bologna, Bologna, Italy
}

\begin{abstract}
In university classrooms a suitable acoustic condition is necessary to enhance the productivity of students and the vocal comfort of lecturers. With this purpose international standards recently introduced new requirements on the quality of verbal communication. The goal of this work is to propose a procedure for predicting speech intelligibility in large learning spaces through geometrical acoustic simulations. The performance of the present approach is investigated using analytical prediction models as well as the measurements results in six university classrooms surveyed.
\end{abstract}

\section{Introduction}

The acoustic design of a classroom should aim at providing suitable conditions for a good verbal communication between lecturers and students (Ricciardi and Buratti (2018), Leccese et al. (2018)). A proper environmental comfort is necessary to minimise the vocal effort for speakers and to facilitate the speech reception for listeners (Visentin et al. (2018), Astolfi et al. (2015), Pelegrín-García et al. (2011), Puglisi et al. (2018)). Several European regulations on classroom acoustics have been recently updated including intelligibility criteria requirements, as summarised by Pelegrín-García et al. (2014). The recent version of the Italian standard UNI 11532 (UNI (2018)), taking target ranges from BB93 (Building Bulletin (1993)) and DIN 18041 (Deutsche Institut für Normung (2016)), is an example of international trends. A proper acoustic condition should give support to the speaker voice without compromising the intelligibility at the listener positions. The objective and measurable criteria usually considered as descriptors of the verbal communication quality are the reverberation time $\left(\mathrm{T}_{20}\right)$, the early-to-late index $\left(\mathrm{C}_{50}\right)$ and the Speech Transmission Index (STI). Due to the significant role of the early reflected energy for the intelligibility of spoken words, it is a common practice to assess $T_{20}$, i.e. the reverberation time taken from $-5 \mathrm{~dB}$ to $-25 \mathrm{~dB}$ below the initial level of the decay curve and then extrapolated to a decay time of $60 \mathrm{~dB}$. Among the several theories and regulations stating the suitable range for the intelligibility parameters in a classroom, the methods provided by UNI 11532 (UNI (2018)) were taken as reference point in the present work. The suitable range of $\mathrm{T}_{20}$ values depends on the volume of the hall and it is considered in occupied conditions (80\% of total occupancy). Generally in large classrooms $\left(V>500 \mathrm{~m}^{3}\right)$ $\mathrm{T}_{20}$ target range turns out to be between 0.70 and 0.90 seconds, according to the method proposed by DIN 18041 (Deutsche Institut für Normung (2016)) and then adopted by UNI 11532 (UNI (2018)). The early-to-late index is defined as (EN ISO (2008)):

$$
C_{50}=10 \log \frac{\int_{0}^{50} p(t)^{2} \mathrm{~d} t}{\int_{50}^{\infty} p(t)^{2} \mathrm{~d} t}
$$

where 50 is assumed as the threshold between early and late sound energy arriving and $p(t)$ is the instantaneous sound pressure of the impulse response. In large lecture halls $\mathrm{C}_{50}$ should assume a value greater than $0 \mathrm{~dB}$ to ensure a proper speech clarity (UNI (2018)). The Speech Transmission Index is a parameter describing how much the speech is deteriorated by the reverberation time and the background noise of the room considered (BS EN (2011)). It is the result of the weighted contributions of individual frequency bands and its range spans from 0 (worst condition) to 1 (best condition), both the limit values representing ideal and theoretical cases. The minimum value recommended for STI values is 0.60 , that is the threshold of "good" intelligibility according to to the ranking provided by IEC 60268-16 (BS EN (2011)).

In order to predict the intelligibility parameters in the acoustic design phase of a classroom, analytical prediction models are provided (UNI (2018)). Nevertheless predicted STI values remain hard to be found out in advance because quite complex evaluations are required. Annex L in IEC 60268-16 (BS EN (2011)) provides an indirect method for analytically calculating STI values based on the use of measured impulse responses and on the assumption of an ideal diffuse reverberant field. The modulation transfer function 
$m_{k}\left(f_{m}\right)$, the basis of STI calculation, is defined as:

$$
m_{k}\left(f_{m}\right)=\frac{\left|\int_{0}^{\infty} h_{k}(t)^{2} e^{-j 2 \pi f_{m} t} \mathrm{~d} t\right|}{\int_{0}^{\infty} h_{k}(t)^{2} \mathrm{~d} t}\left[1+10^{-\mathrm{SNR}_{k} / 10}\right]^{-1}
$$

where $h_{k}(t)$ is the impulse response of $k$-octave band, $t$ is the integration variable for time, $f_{m}$ is the modulation frequency and $\mathrm{SNR}_{k}$ is the signal-to-noise ratio in $\mathrm{dB}$. Equation 2 shows how the modulation transfer function $m_{k}\left(f_{m}\right)$ is affected by two terms: the room acoustics (impulse response) and the signal-to-noise ratio (SNR), i.e. the difference between the sound pressure level at the receiver and the background noise. Consequently given a certain room acoustics the quality of the speech communication depends mainly on SNR, as may be confirmed also by measurements carried out by D'Orazio et al. (2018) and Choi (2017). According to Annex L of IEC 60268-16 (BS EN (2011)), under the assumption of a diffuse reverberant field the impulse response for each octave band may be written as:

$$
h(t)=\frac{Q}{r^{2}} \delta(t)+\frac{13.8 Q}{r_{c}^{2} T} e^{-13.8 t / T}
$$

where $Q$ is the directivity factor of the sound source ( $Q=1$ for omnidirectional sound source), $r$ is the source-receiver distance in meters, $\delta(t)$ is the delta function, $r_{c}$ is the critical radius of the room in meters, $T$ is the predicted reverberation time of the room in seconds. Therefore the modulation transfer function $m\left(f_{m}\right)$ for each octave band may be simplified as:

$$
m\left(f_{m}\right)=\frac{\sqrt{A^{2}+B^{2}}}{C}
$$

with the components $A, B$ and $C$ expressed as:

$$
\begin{gathered}
A=\frac{Q}{r^{2}}+\frac{1}{r_{c}^{2}}\left[1+\left(\frac{2 \pi f_{m} T}{13.8}\right)^{2}\right]^{-1} \\
B=\left(\frac{2 \pi f_{m} T}{13.8 r_{c}^{2}}\right)\left[1+\left(\frac{2 \pi f_{m} T}{13.8}\right)^{2}\right]^{-1} \\
C=\frac{Q}{r^{2}}+\frac{1}{r_{c}^{2}}+Q \cdot 10^{-\mathrm{SNR} / 10}
\end{gathered}
$$

Since the diffuse sound field may be an assumption too distant from the actual behaviour of the sound field in a classroom, several studies attempted to lead back the prediction of STI to the prediction of simpler parameters, such as reverberation time (Leccese et al. (2018), Escobar and Morillas (2015), Nowoświat and Olechowska (2016)). Nevertheless the reverberation time is a quite constant parameter in a room while the speech intelligibility significantly varies moving away from the sound source. This effect is even greater if the acoustics of the room is poor, as frequently is in existing ancient buildings unsuitable for teaching purpose. A parameter that varies roughly in the same way throughout the space is the sound pressure level that - in a normalised form - is the sound strength G defined by ISO 3382-1 (EN ISO (2009)). Therefore it could be helpful to assess the sound pressure level propagation in order to understand the speech intelligibility trend throughout the space. Several studies investigated the spatial distribution of the sound pressure level and how its behaviour varies depending on different kind of spaces. From a global point of view the sound pressure level in a certain position is the sum of a direct component and a reflected one. While the direct sound field is equally decreasing for all the expressions of $\mathrm{G}$ as a function of source-to-receiver distance, the reflected energy trend varies depending on the theory assumed. According to the classical semi-reverberant theory the sound strength may be expressed as:

$$
G(r)=10 \log \left(d+31200 \frac{T}{V}\right)
$$

where $r$ is the source-receiver distance in meters, $d$ is the energy of direct sound component $\left(d=100 / r^{2}\right)$, $T$ is the reverberation time in seconds, and $V$ is the volume of the hall in $\mathrm{m}^{3}$. In this case the reverberant term is constant throughout the space because it depends only on constant factors, i.e. the reverberation time and the volume. The concept of a diffuse sound field represents a fundamental reference concept in room acoustics but its requirements are rarely achievable. Barron and Lee (1988) introduced the revised theory as a result of several studies conducted on concert halls. The total refleceted sound level decreases with the increasing of source-to-receiver distance, as shown in the expression:

$$
G(r)=10 \log \left(d+31200 \frac{T}{V} e^{-0.04 r / T}\right)
$$

where $e^{-0.04 r / T}$ is the exponential decay of the reflected component. After Barron and Lee (1988) several studies reported different coefficient values for the exponential decay in order to adapt the model to other typologies of enclosed spaces. In a certain sense the distribution of sound strength may be considered as a trait of each kind of hall. For what concerns the university classrooms Sato and Bradley (2008) found out that the sound strength expression was:

$$
G(r)=10 \log \left(d+31200 \frac{T}{V} e^{-(2 \cdot 0.04) r / T}\right)
$$

meaning that reflected energy decreases twice as rapidly with the distance as in the revised theory. The slope of the decay becomes steeper with the presence of highly diffusing items such as desks and chairs, i.e. scattering elements that contribute to decrease more rapidly the sound propagation throughout the space. In the following sections a method for predicting $G$ trend through numerical simulations is described and assessed. 


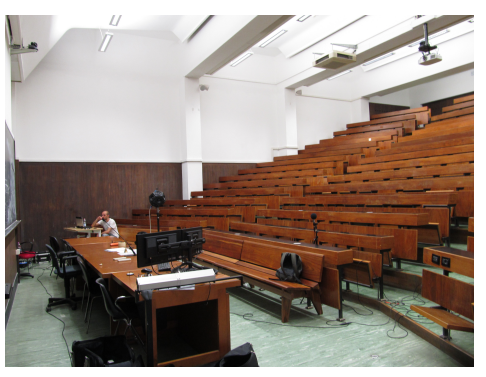

(a)

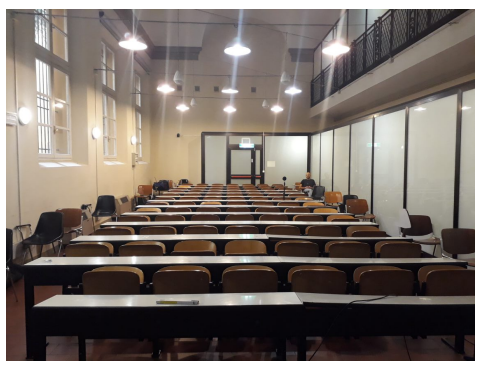

(d)

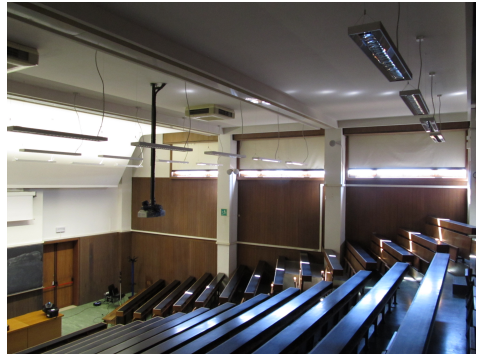

(b)

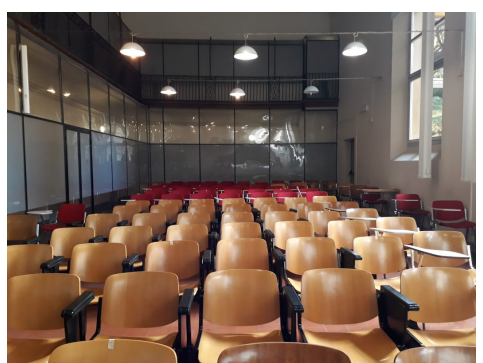

(e)

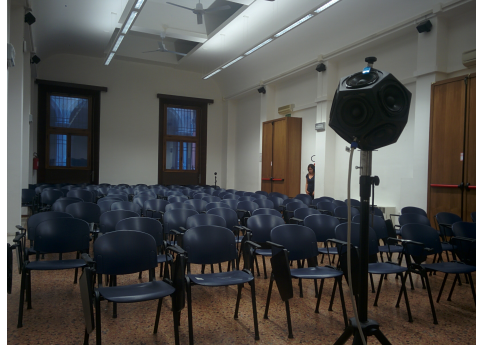

(c)

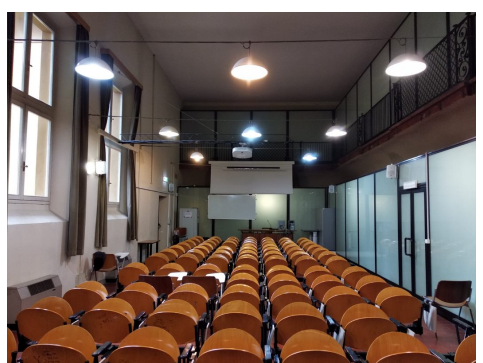

(f)

Figure 1: Inside views of the lecture halls surveyed (July 2017 - October 2018).

Table 1: Main data of the lecture halls surveyed ( $\mathrm{V}=$ volume, $\mathrm{S}_{\mathrm{A}}=$ students area, $\mathrm{N}=$ occupancy). Measured $\mathrm{T}_{20}$ values are averaged in the range 500-1000 Hz while measured $\mathrm{C}_{50}$ in the range 125-4000 Hz. The occupied conditions ("occ") are calculated with the method provided by UNI 11532 (UNI (2018)).

\begin{tabular}{ccccccccc}
\hline Hall & $\mathrm{V}\left(\mathrm{m}^{3}\right)$ & Shape & Seats & $\mathrm{S}_{\mathrm{A}}\left(\mathrm{m}^{2}\right)$ & $\mathrm{N}$ & $\mathrm{T}_{20, \text { occ }}(\mathrm{s})$ & $\mathrm{C}_{50}(\mathrm{~dB})$ & $\mathrm{STI}$ \\
\hline$a$ & 1000 & Amphiteatre & Wood & 110 & 250 & 0.90 & -2.5 & 0.48 \\
$b$ & 900 & Amphiteatre & Wood & 95 & 200 & 0.99 & -1.9 & 0.49 \\
$c$ & 850 & Shoe-box & Plastic & 80 & 170 & 1.22 & -4.1 & 0.43 \\
$d$ & 910 & Shoe-box & Wood & 35 & 90 & 1.70 & -3.3 & 0.44 \\
$e$ & 780 & Shoe-box & Wood & 40 & 90 & 1.83 & -4.4 & 0.41 \\
$f$ & 800 & Shoe-box & Wood & 55 & 105 & 1.30 & -2.1 & 0.50 \\
\hline
\end{tabular}

\section{Method}

The aim of the present study is to analyse the accuracy of speech intelligibility criteria predictions obtained with geometrical acoustic simulation techniques. A measurements campaign was performed in six university lecture halls to get a series of reference data during the work (see Figures 1-2). The calibration of $3 \mathrm{D}$ virtual models was carried out achieving the match between measured and simulated reverberation time (see Figures 3-4). The mutual match between measured, simulated and predicted $\mathrm{G}$ values confirms that geometrical acoustic simulations could be able to give accurate information on normalized sound pressure level spatial distribution (see Figure 5). Measured STI and G values displayed as functions of source-to-receiver distance show a significant relation between speech intelligiblity and sound pressure level decays (see Figure 6). Therefore it could be suggested that the knowledge of $\mathrm{G}$ spatial trend may allow to get reliable information on STI trend, overcoming the difficulties of STI prediction models' calculations.

\section{Case studies}

The present study is conducted in a sample of six lecture halls of the University of Bologna located in historical buildings of the city centre. They are charaterised by large volumes (greater than $500 \mathrm{~m}^{3}$ ) including up to 250 occupants. Of the six classrooms, two $(a$ and $b)$ have an amphiteatre shape while the other four $(c, d, e, f)$ have a quite regular shoe-box geometry except for the presence of small coupled volumes in the ceiling or in the side walls (see Figure 1). All the classrooms have similar surface finishes with sound reflecting materials such as smooth plastered walls, large windows placed on only one side of the halls and wooden (or plastic) seats, not counting a small part of the audience of hall $e$ with slightly upholstered seats. Table 1 shows the main data of the six lecture halls including the volume, the shape, the materials and the occupancy.

\section{Measurements}

Between 2017 and 2018, more acoustic measurements campaigns were performed in the lecture halls surveyed to collect objective speech intelligibility criteria. Measurements were conducted in full furnished 


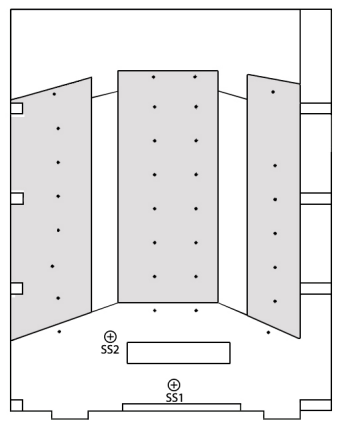

(a)

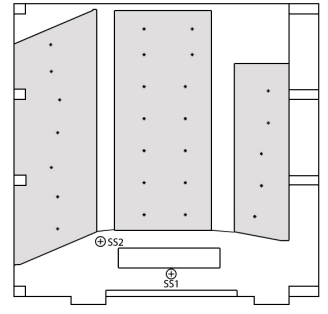

(b)

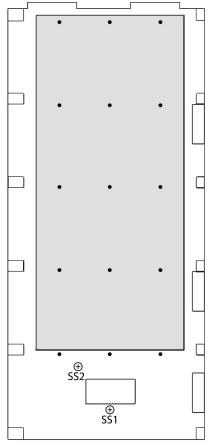

(c)

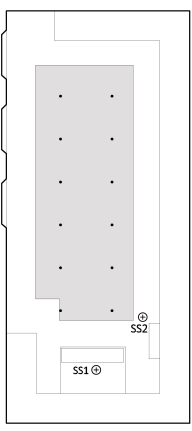

(d)

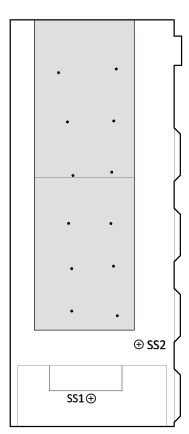

(e)

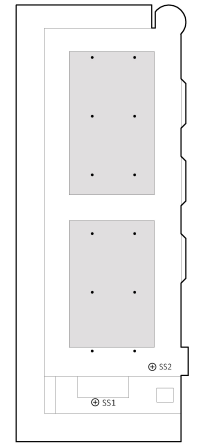

(f)

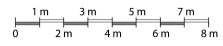

Figure 2: Plans of the lecture halls under study: positions of sound sources (SS1, SS2) and receivers grids selected for the acoustic measurements setup.

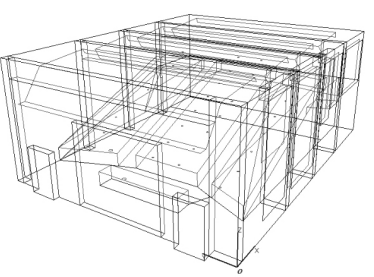

(a)

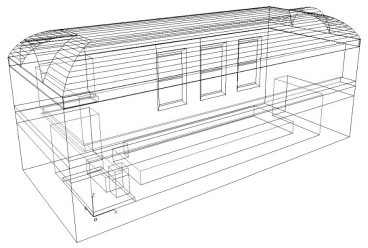

(d)

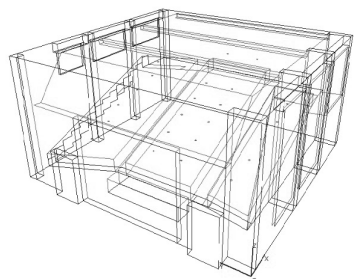

(b)

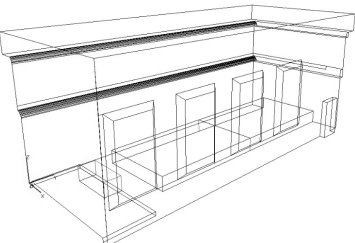

(e)

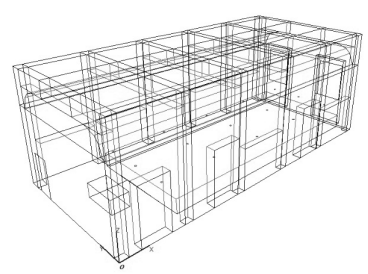

(c)

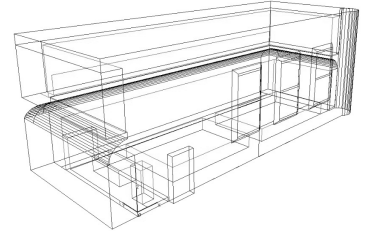

(f)

Figure 3: View of numerical 3D models during the geometrical acoustic simulations.

condition and in unoccupied states complying with ISO 3382-2 (EN ISO (2008)). Monaural impulse responses were acquired using the Exponential Sine Sweep technique, with a signal $512 \mathrm{~K}$ in length and sampled at $48 \mathrm{kHz}$ (Guidorzi et al. (2015)). A highSPL dodecahedron was used as omnidirectional sound source (D'Orazio et al. (2016)), rotated three times for each impulse response acquisition (Martellotta (2013)) in order to remove directivity factors of single loudspeakers as much as possible. The sound source was previously calibrated in a certified reverberation room according to ISO 3741 (UNI EN ISO (2010)). Two sound sources positions and a regular grid of receivers points were chosen for the measurements setup (see Figure 2). The extrapolation of data was conducted with B\&K's Dirac 6 software (Brüel and Kjær (2014)) and an accurate analysis was carried out on $\mathrm{T}_{20}, \mathrm{C}_{50}, \mathrm{G}$ and STI, using for the latter the indirect method according to IEC 60268-16 (BS EN (2011)). In each receiver position and in each octave band the difference between the sound pressure level received and the background noise was greater than
$20 \mathrm{~dB}$, allowing to ignore the background noise level for focusing just on the signal received in each position (Hodgson and Wong (2009)).

\section{Numerical simulation}

The lecture halls surveyed represent a typology of rooms particularly suitable for numerical simulations due to their large volumes and quite regular shapes. The modelling process of approximation required in Geometrical Acoustic (GA) techniques is thus facilitated enhancing the reliability of all the simulations. The 3D models of the university classrooms were created using 3D SketchUp and then imported into ODEON Room Acoustics software (see Figure 3). The modelling process was carried out according to the state-of-the-art recommendations (Vorländer (2007)). Concerning the level of detail needed for the simulations, modelled surfaces were kept greater than $0.35 \mathrm{~m}$ following guidelines by Christensen (2011). Sound absorption coefficients were provided by materials databases present in previous scientific literature (Vorländer (2007), Cox and d'Antonio (2016)) and 
Table 2: Absorption $(\alpha)$ and scattering $(s)$ coefficients for the main materials involved in simulation process (Cox and d'Antonio (2016), Vorländer (2007)).

\begin{tabular}{cccccccc}
\hline Materials & & $125 \mathrm{~Hz}$ & $250 \mathrm{~Hz}$ & $500 \mathrm{~Hz}$ & $1000 \mathrm{~Hz}$ & $2000 \mathrm{~Hz}$ & $4000 \mathrm{~Hz}$ \\
\hline \multirow{2}{*}{ Plaster-Floor } & $\alpha$ & 0.02 & 0.02 & 0.03 & 0.03 & 0.04 & 0.06 \\
& $\mathrm{~s}$ & 0.01 & 0.01 & 0.02 & 0.10 & 0.20 & 0.25 \\
Seats & $\alpha$ & 0.22 & 0.10 & 0.07 & 0.12 & 0.13 & 0.17 \\
& $\mathrm{~s}$ & 0.01 & 0.10 & 0.45 & 0.65 & 0.78 & 0.82 \\
\hline
\end{tabular}

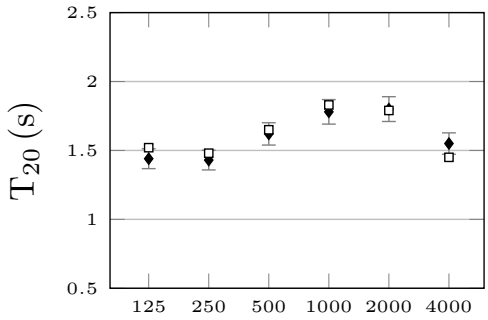

(a)

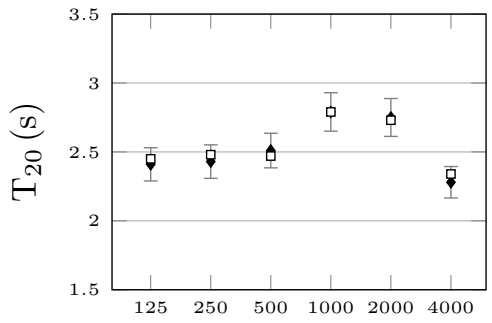

(d)

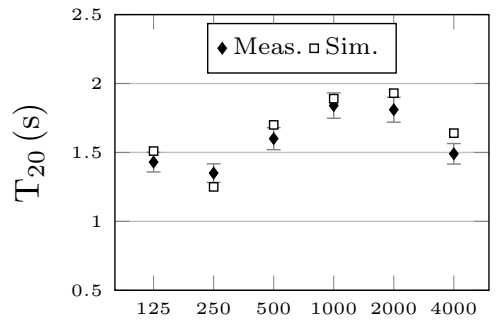

(b)

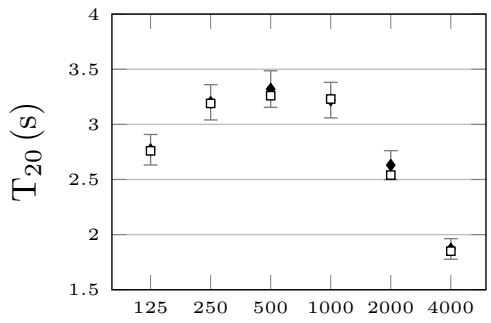

(e)

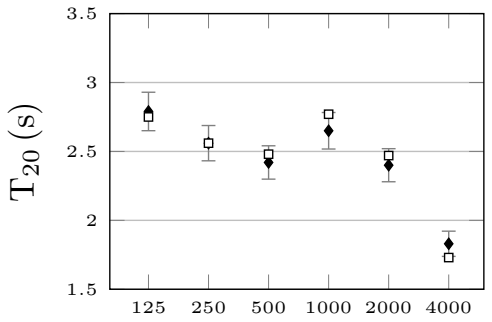

(c)

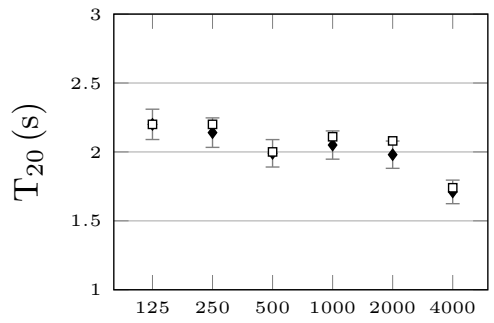

(f)

Figure 4: Calibration of geometrical acoustic models: measured and simulated mean $\mathrm{T}_{20}$ values in unoccupied conditions as a function of the frequency. $\mathrm{T}_{20}$ values are averaged over all the source-receivers couples. The error bars are referred to the Just Noticeable Difference (JND) defined by ISO 3382-1 EN ISO (2009).

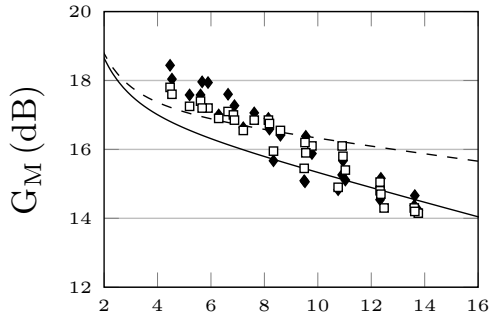

(a)

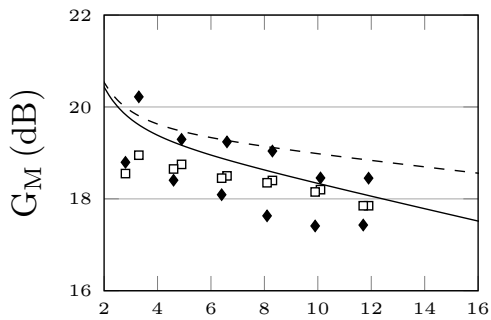

(d)

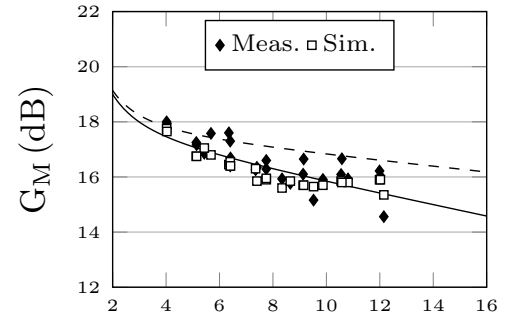

(b)

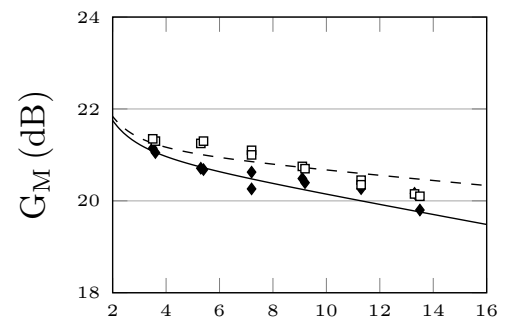

(e)

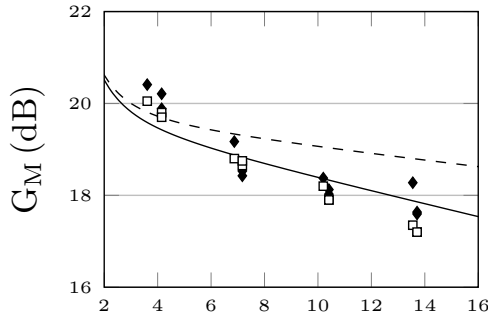

(c)

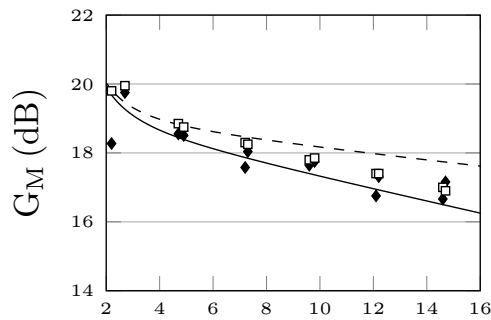

(f)

Figure 5: Calibration of geometrical acoustic models: measured and simulated $\mathrm{G}_{\mathrm{M}}$ values as functions of sourceto-receiver distance. "M" subscript indicates the values averaged over the central octave-bands $500-1000 \mathrm{~Hz}$. Dashed and solid curves are respectively the Barron and Lee (1988) curve (see Equation 9) and the adjustment for university classrooms by Sato and Bradley (2008) (see Equation 10). 
then adjusted through the calibration iterative process, according to a consolidated procedure (Astolfi et al. (2008)). Given that GA softwares describe the sound propagation along sound rays, the wave nature of sound had to be introduced by assigning scattering properties to each surface (Rindel (2000)). In particular, scattering coefficients took into account both the surface roughness and the occurence of edges, compensating in this way the lack of details due to the simplification of the models. In order to simplify the whole procedure and reduce the uncertainty of input data for materials properties an attempt was made to reduce as much as possible the number of the layers used. During the workflow the layers were mainly divided in those ones characterised by higher absorption and scattering coefficients (seats) and all the other ones characterised by sound reflective and smooth surfaces (walls, floors, ceilings), as shown in Table 2. The numerical models were calibrated ensuring the match between measured and simulated values (see Figures 4-5). The calibration was considered to be achieved when the difference between measured and simulated values was within one Just Noticeable Difference (JND) according with ISO 3382-1 (EN ISO (2009)).

\section{Results}

The last three columns of Table 1 show the overview on main measurements results where mean values are averaged over all source-receiver positions. Measured reverberation time $\left(\mathrm{T}_{20}\right)$, sound clarity $\left(\mathrm{C}_{50}\right)$ and speech intelligibility (STI) values indicate that each of the halls investigated present quite poor acoustic conditions for a suitable speech intelligibility. Nevertheless the aim of this work is to analyse the acoustics of typical university classrooms, often located in historical buildings that turn out to be unsuitable for the purpose. In order to assess the actual sound field behaviour of the lecture halls under study the $3 \mathrm{D}$ virtual models were calibrated basing on reverberation time in octave bands and the normalised sound pressure level as a function of source-to-receiver distance. Figures 4 and 5 provide the comparison between measured $\mathrm{T}_{20}$ and $\mathrm{G}_{\mathrm{M}}$ values and simulated ones. The error bars displayed in $\mathrm{T}_{20}$ graphs are referred to the JND defined by ISO 3382-1 (EN ISO (2009)). The dashed and solid curves displayed in $\mathrm{G}_{\mathrm{M}}$ graphs are referred to analytical prediction models, respectively the Barron and Lee (1988)'s curve (see Equation 9) and the adjustment for university classrooms by Sato and Bradley (2008) (see Equation 10). Results show a good agreement between measurements and simulated values allowing to consider reliable the calibration procedure used. Concerning the spatial distribution of sound pressure level the match with the specific prediction model developed for university classrooms confirms that the halls surveyed present the typical sound field behaviour of large learning spaces.

\section{Discussions}

As mentioned in the introduction the modulation transfer function, which is the basis of STI definition, mainly depends on two factors, the first concerning the room acoustics characteristics (impulse responses), and the second concerning the difference between the sound pressurel level received and the background noise (SNR). Given a certain room acoustics, namely a certain impulse response, the deterioration of the modulation transfer functions is affected only by the sound pressure level at the receiver position considered. This is confirmed by the similar trend of linear regressions of measured STI and $\mathrm{G}_{\mathrm{M}}$ plotted as functions of source-to-receiver distance (see Figure 6). Nevertheless a good match between the regression lines is obtained neglecting receivers that are closer than 4 meters from the sound source, to assure that the reflected energy is prevalent rather than the direct one (see gray rectangles in Figure 6). It is possible to deduce that the critical radius of an actual room - defined as the distance at which the sound pressure level of the direct sound and the reverberant sound are equal - is greater than the traditional formula $r_{c}=0.057 \sqrt{V / T}(\mathrm{~m})$ (with $V$ as the volume of the room in $\mathrm{m}^{3}$ and $T$ as the reverberation time in seconds) derived by classical semi-reverberant theory. It also means that the halls must be large enough for this kind of decay analysis. A reliable geometrical acoustical model, obtained with a simplified but rigorous procedure, may be considered an useful tool for validating the prediction of speech intelligibility by the analysis of sound pressure level spatial distribution. For this reason the calibration of geometrical acoustic models has been conducted taking into account the decay of sound pressure level with the increasing of source-to-receiver distance, as shown in Figure 5. A further analysis could also involve the comparison between STI and the early component of the total sound energy $\left(\mathrm{G}_{\text {early }}\right)$ considering the integration time at $50 \mathrm{~ms}$ (De Cesaris et al. (2015)), due to the relevance of this time interval for speech criteria.

\section{Conclusions}

The acoustic design of a classroom is an important issue because the reduction of the vocal effort for teachers and the increasing of the attention for students are quite significant aspects of the learning process. In order to predict the quality of verbal communication a preliminary approach based on geometrical acoustic simulations is here proposed. The data obtained by a measurements campaign conducted in six university lecture halls has been taken as reference point for the assessment of sound field behaviours and for the calibration process. The sample of university lecture halls considered in the present work represent a typology suitable for analysing the decay of the sound pressure level and consequently for connecting the 


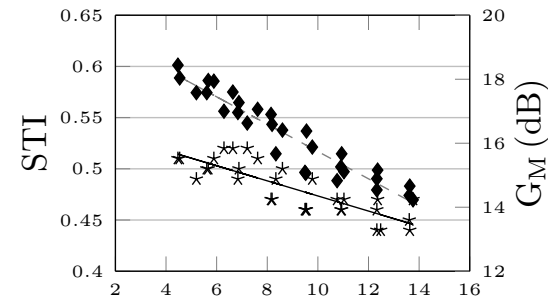

(a)

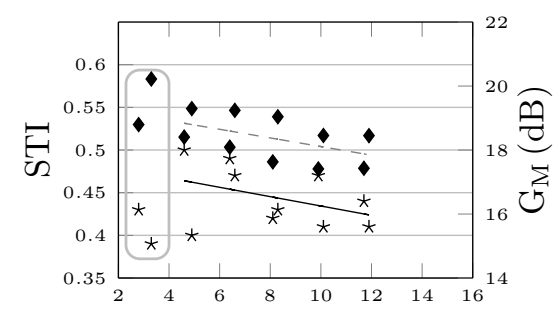

(d)

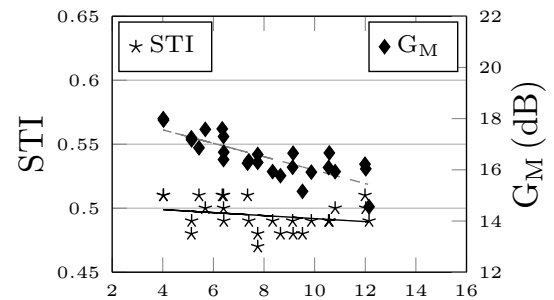

(b)

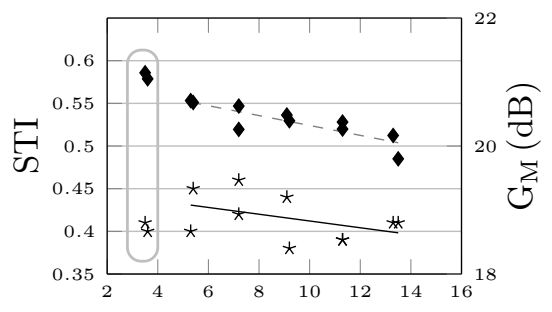

(e)

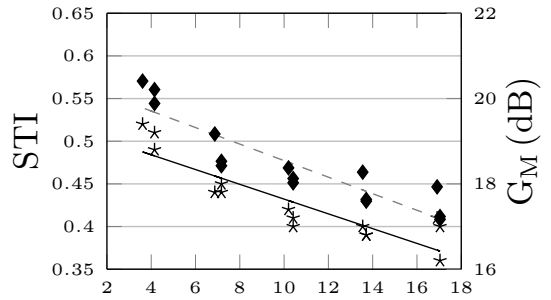

(c)

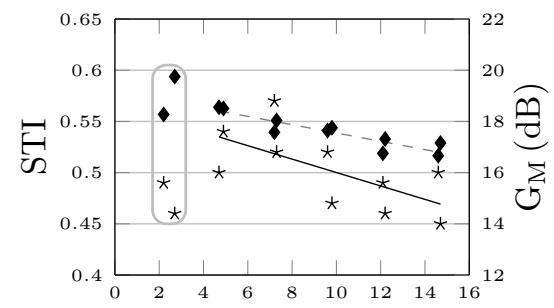

(f)

Figure 6: Measured STI and $\mathrm{G}_{\mathrm{M}}$ values plotted as function of the source-to-receiver distance. "M" subscript indicates the values averaged over the central octave-bands $500-1000 \mathrm{~Hz}$. Linear regressions of data are plotted excluding the values within 4 meters from the sound source (in rectangles).

sound propagation losses to the variations of speech intelligiblity throughout the space. The accuracy of simulated $\mathrm{G}$ spatial distributions and the similarity between $\mathrm{G}$ and STI trends suggest the possibility to get important information on speech intelligibility decays even in a preliminary acoustic design phase. A larger sample of lecture halls surveyed could allow to enhance the statistical significance of the model proposed.

\section{References}

Astolfi, A., A. Carullo, L. Pavese, and G. E. Puglisi (2015). Duration of voicing and silence periods of continuous speech in different acoustic environments. The Journal of the Acoustical Society of America 137(2), 565-579.

Astolfi, A., V. Corrado, and A. Griginis (2008). Comparison between measured and calculated parameters for the acoustical characterization of small classrooms. Applied Acoustics 69(11), 966-976.

Barron, M. and L.-J. Lee (1988). Energy relations in concert auditoriums. i. The Journal of the Acoustical Society of America 84(2), 618-628.

Brüel and Kjær (2014). Dirac room acoustics software version 6.0 .

British Standards Institute (2011). Sound system equipment-Part 16: Objective rating of speech intelligibility by speech transmission index (BS EN 60268-16).

Building Bulletin (1993). Acoustic design of schools - A design guide (BB 93).
Choi, Y.-J. (2017). Predicting classroom acoustical parameters for occupied conditions from unoccupied data. Applied Acoustics 127, 89-94.

Christensen, C. L. (2011). Odeon room acoustics software ver. 11. User manual: Industrial, auditorium and combined editions. Odeon A/S, Lyngby, Denmark.

Cox, T. and P. d'Antonio (2016). Acoustic absorbers and diffusers: theory, design and application. Crc Press.

De Cesaris, S., F. Morandi, L. Loreti, D. D'Orazio, and M. Garai (2015). Notes about the early to late transition in italian theatres. Proc. of ICSV22, Florence.

Deutsche Institut für Normung (2016). Acoustic Quality in Rooms- Specifications and Instructions for the Room Acoustic Design. (DIN 18041).

D'Orazio, D., S. De Cesaris, P. Guidorzi, L. Barbaresi, M. Garai, and R. Magalotti (2016). Room acoustic measurements using a high-spl dodecahedron. In Audio Engineering Society Convention 140. Audio Engineering Society.

D'Orazio, D., E. Rossi, and M. Garai (2018). Comparison of different in situ measurements techniques of intelligibility in an open-plan office. Building Acoustics 25(2), 111-122.

International Organisation for Standardisation (2008). Acoustics - Measurement of Room Acoustic Parameters - Part 2: Reverberation Time in Ordinary Rooms (EN ISO 3382-2). 
International Organisation for Standardisation (2009). Acoustics - Measurement of Room Acoustic Parameters - Part 1: Performance Spaces (EN ISO 3382-1).

Escobar, V. G. and J. B. Morillas (2015). Analysis of intelligibility and reverberation time recommendations in educational rooms. Applied Acoustics 96, $1-10$.

Guidorzi, P., L. Barbaresi, D. D'Orazio, and M. Garai (2015). Impulse responses measured with mls or swept-sine signals applied to architectural acoustics: an in-depth analysis of the two methods and some case studies of measurements inside theaters. Energy Procedia 78, 1611-1616.

Hodgson, M. and G. Wong (2009). Ray-tracing prediction of optimal conditions for speech in realistic classrooms. Applied Acoustics 70(7), 915-920.

Leccese, F., M. Rocca, and G. Salvadori (2018). Fast estimation of speech transmission index using the reverberation time: Comparison between predictive equations for educational rooms of different sizes. Applied Acoustics 140, 143-149.

Martellotta, F. (2013). Optimizing stepwise rotation of dodecahedron sound source to improve the accuracy of room acoustic measures. The Journal of the Acoustical Society of America 134(3), 2037-2048.

Nowoświat, A. and M. Olechowska (2016). Fast estimation of speech transmission index using the reverberation time. Applied Acoustics 102, 55-61.

Pelegrín-García, D., B. Rasmussen, and J. Brunskog (2014). Classroom acoustics design for speakers' comfort and speech intelligibility: a european perspective. In Proceedings of Forum Acusticum 2014.

Pelegrín-García, D., B. Smits, J. Brunskog, and C.-H. Jeong (2011). Vocal effort with changing talkerto-listener distance in different acoustic environments. The Journal of the Acoustical Society of America 129(4), 1981-1990.

Puglisi, G. E., A. Prato, T. Sacco, and A. Astolfi (2018). Influence of classroom acoustics on the reading speed: A case study on italian secondgraders. The Journal of the Acoustical Society of America 144 (2), 144-149.

Ricciardi, P. and C. Buratti (2018). Environmental quality of university classrooms: Subjective and objective evaluation of the thermal, acoustic, and lighting comfort conditions. Building and Environment 127, 23-36.

Rindel, J. H. (2000). The use of computer modeling in room acoustics. Journal of vibroengineering 3(4), 219-224.
Sato, H. and J. S. Bradley (2008). Evaluation of acoustical conditions for speech communication in working elementary school classrooms. The Journal of the Acoustical Society of America 123(4), 2064-2077.

Ente Nazionale Italiano di Unificazione (2018). Caratteristiche acustiche interne di ambienti confinatiMetodi di progettazione e tecniche di valutazioneParte 1: Requisiti generali (UNI 11532-1).

International Organisation for Standardisation (2010). Acoustics - Determination of sound power levels and sound energy levels of noise sources using sound pressure - Precision methods for reverberation test rooms (UNI EN ISO 3741).

Visentin, C., N. Prodi, F. Cappelletti, S. Torresin, and A. Gasparella (2018). Using listening effort assessment in the acoustical design of rooms for speech. Building and Environment 136, 38-53.

Vorländer, M. (2007). Auralization: fundamentals of acoustics, modelling, simulation, algorithms and acoustic virtual reality. Springer Science \& Business Media. 